\title{
İntrameduller çivi uygulamasında erken yük vermenin kırık kaynamasına etkisi
}

\author{
Impact of early loading on fracture healing with intramedullary nailing
}

\author{
Nusret Ök, Bekir Alper Kılıç, Ahmet Fahir Demirkan, Ali Çağdaş Yörükoğlu, Mehmet Yücens, Ahmet \\ Nadir Aydemir, Harun Reşit Güngör, Nihal Büker
}

Gönderilme tarihi:12.07.2018

Kabul tarihi:16.11.2018

Özet

Amaç: Tibia cisim kırıkları, ortopedi ve travmatoloji pratiğinde en sık görülen kırık tiplerinden biridir. Bu çalışmada tibia cisim kırıkları tedavisinde kilitli intramedüller çivi uygulanan hastaların klinik sonuçlarının ve fonksiyonel durumlarının değerlendirilmesi ve yük verme ile kaynama zamanının karşılaştırııması amaçlanmıştır.

Gereç ve yöntem: Çalışmaya 18-73 yaş arası, tibia cisim kırığı nedeni ile intramedüller fiksasyon uygulanmış olan 44 hasta dahil edildi. Çalışmamızda sonuçlar, Johner ve Wruhs kriterlerine göre ve Karlstum-Olerud kriterlerine göre kaydedildi. Radyolojik olarak iyileşme, radyografilerde hastanın desteksiz olarak yük verebileceği düzeyde kallus formasyonu ve/veya kırık hattının kaybolması olarak değerlendirildi. Klinik iyileşme ise hastanın ağrısız tam yük verebilmesi ve günlük aktivitelerine dönebilmesi olarak değerlendirildi.

Bulgular: Hastaların yaş ortalaması $38.7 \pm 14.9$ (17-73) yıl idi. 44 hastanın 16' sında (\%36.4) tibia 1/3 orta cisim kırığı, 25' inde (\%56.8) tibia 1/3 distal kırık, 3'ünde ise (\%6.8) ise tibia 1/3 proksimal kırığı mevcuttu. Hastaların ortalama kaynama süresi $11.36 \pm 3.8(6-20)$ hafta olarak gözlendi. Karlstrom-Olerud'un fiziksel fonksiyonel değerlendirme skalasına göre; 21 hasta (\%47.7) mükemmel, 14 hasta (\%31.8) iyi, 1 hasta (\%2.3) tatmin edici, 8 hasta (\%18.2) ise orta olarak kaydedildi ve hiç kötü sonuç yoktu. Johner-Wrush kriterlerine göre 32 hastada (\%72.7) mükemmel, 12 hastada ise \%27.3 iyi olarak değerlendirildi. Takip sürecinde bütün kırıkların kaynadığı gözlendi.

Sonuç: Hastalar Johner-Wrush Kriterlerine göre mükemmel ve iyi skora sahiptiler. Karlstrom-Olerud'un fiziksel fonksiyonel değerlendirme skalasına göre ise hiçbir hasta kötü skora sahip değildi. Genç, erken ağırlık aktaran ve çivi korteks mesafesi $2 \mathrm{~mm}$ 'den az olan hastalarda kaynama süresi kısalmaktadır.

Anahtar Kelimeler: Tibia cisim kırıkları, kilitli intramedüller çivileme, yük verme.

Ök N, Kılıç BA, Demirkan AF, et al. İntrameduller çivi uygulamasında erken yük vermenin kırık kaynamasına etkisi. Pam Tıp Derg 2019;12:61-66.

\footnotetext{
Abstract

Purpose: Tibial diaphyseal fractures are one of the most common types of fractures in practise of the orthopedics and traumatology. In this study, clinical results of the patients with diaphyseal fractures of the tibia which have been treated with locking intramedullary nailing tecnique and the weight bearing time and union time has been evaluated.

Materials and methods: Patients who applied to our hospital with tibial diaphyseal fractures were evaluated retrospectively. 43 patients were included in the study. Karlstrom-Olerud, Johner and Wruhs score were used to evaluate clinical results. Radiologic improvement was assessed as loss of callus formation and / or fracture line at the level that the patient could load without support on radiographs. Clinical improvement was assessed as the patient was able to give full pain relief and return to daily activities.

Results: Mean duration of union was 11.36 $\pm 3.8(6-20)$ weeks. According to Karlstrom-Olerud, 21 patients $(47.7 \%)$ has received a full grade of 36,14 patients $(31.8 \%)$ have been evaluated as good with a grade between

Nusret Ök, Dr.Öğr.Üyesi, Pamukkale Üniversitesi Tıp Fakültesi Ortopedi Travmatoloji Ana Dalı, DENiZLi, e-posta:oknusret@gmail.com (orcid. org/0000-0003-3811-1884) (Sorumlu yazar)

Bekir Alper Kılıç, Prof.Dr. Florance Nightengale Tıp Merkezi Kadıköy, ISTANBUL, e-posta:kilicbekiralper@gmail.com (orcid.org/0000-00030072-8440)

Ahmet Fahir Demirkan, Prof.Dr. Pamukkale Üniversitesi Tıp Fakültesi Ortopedi Travmatoloji, DENiZLi, e-posta:fahirdemirkan@yahoo.com (orcid.org/0000-0002-1393-7068)

Ali Çağdaş Yörükoğlu, Dr.Öğr.Üyesi, Pamukkale Üniversitesi Tıp Fakültesi Ortopedi Travmatoloji Ana Dalı, DENiZLi,

e-posta:alicagdasyorukoglu@gmail.com (orcid.org/0000-0001-8903-3578)

Mehmet Yücens, Dr.Öğr.Üyesi, Pamukkale Üniversitesi Tıp Fakültesi Ortopedi Travmatoloji Ana Dalı, DENiZLİ, e-posta:aflyucens@yahoo. com (orcid.org/0000-0001-6924-6613)

Ahmet Nadir Aydemir, Dr.Öğr.Üyesi, Pamukkale Üniversitesi Tıp Fakültesi Ortopedi Travmatoloji Ana Dalı, DENiZLİ, e-posta:anaydemir@ yahoo.co.uk (orcid.org/0000-0002-3095-4935)

Harun Reşit Güngör, Doç.Dr. Pamukkale Üniversitesi Tıp Fakültesi Ortopedi Travmatoloji Ana Dalı, DENiZLI, e-posta:hrgungor@gmail.com (orcid.org/0000-0002-0721-0890)

Nihal Büker, Doç.Dr. Pamukkale Üniversitesi Fizik Tedavi ve Rehabilitasyon Yüksek Okulu, DENiZLí, e-posta: nasuk@pau.edu.tr (orcid.org 0000-0001-7259-7983)
} 
33 and 35,1 patient $(2.3 \%)$ was satisfactory with a grade in the range $30-32$ and 8 patients were in the range 27-29 and they are evaluated as fair. Non of the patients were evaluated as poor.

Conclusion: Patients have an excellent and good score according to the Johner-Wrush criteria. According to Karlstrom-Olerud's physical functional assessment scale, no patient had a bad scar. Younger, early-weightbearing patients with a nail cortex distance of less than $2 \mathrm{~mm}$, the duration of union is shortening.

Key words: Tibia fracture, Locked intramedullery nail, loading.

Ök N, Kılıç BA, Demirkan AF, et al. Impact of early loading on fracture healing with intramedullary nailing. Pam Med J 2019;12:61-66.

\section{Giriş}

Tibial cisim kırıkları, ortopedi ve travmatoloji pratiğinde en sık görülen uzun kemik kırıklarından biridir [1]. Sıklıkla direkt travma ve motorlu araç kazaları ile oluşur, spor yaralanmalarında indirekt travma ile de oluşabilmektedir. Erkekler kadınlara göre daha sık etkilenir ve genellikle erişkin yaş grubunda görülür [2]. Tibia en sık açık kırık görülen uzun kemiktir. Tibia diğer uzun kemiklere göre daha yüzeyseldir, bu nedenle cerrahiden sonra yara yeri problemleri daha sık görülür. Daha az yumuşak doku örtüsü olması ve görece beslenme yetersizliği nedeniyle kaynamama ve gecikmiş kaynama tibia kırıklarında diğer uzun kemiklere göre daha sık görülür [3, 4]. Tibia cisim kırıklarında kapalı redüksiyon sonrası alçılama, anatomik plakla internal fiksasyon, intramedüller çivileme ve eksternal fiksasyon gibi çeşitli tedavi seçenekleri bulunmaktadır [5]. Bu seçeneklerden intramedüller çivileme, minimal yumuşak doku hasarı, erken eklem hareketleri ve ameliyat sonrası erken yük verme nedeniyle tibia cisim kırıkları için ilk tedavi seçeneğidir [6].

$\mathrm{Bu}$ çalışmada tibia cisim kırıklarının intramedüller çivi ile fiksasyonunun radyolojik ve fonksiyonel sonuçları değerlendirilmesi amaçlanmıştır.

\section{Gereç ve yöntem}

Çalışma için Pamukkale Üniversitesi Girişimsel Olmayan Klinik Araştırmalar Etik Kurulu'ndan 20.09.2010 tarih ve 05 sayılı izin alınmıştır. Hastaların her birinden bilgilendirilmiş gönüllü olur belgesi ile bilgilendirilmişlerdir.

Çalışma 2006-2010 tarihleri arasında, Pamukkale Üniversitesi Eğitim ve Araştırma Hastanesinin, Ortopedi ve Travmatoloji Kliniği'nde tibia cisim kırığı nedeniyle intramedüller fiksasyon uygulanmış ve çalışma kriterlerini karşılayan hastalar telefon ile çalışmaya katılmaları için davet edildi. Eklem bölgesine uzanan distal ve proksimal metafiz kırıkları, geçici eksternal fiksatörlerle tedavi edilen kırıklar ve patolojik kırıklar çalışma dışı bırakıldı. Çalışma kriterlerini karşılayan 51 hastadan 3 hasta çalışmaya katılmak istemediği için, 5 hastanın da değerlendirmeleri tamamlanamadığı için çalışma dışı bırakılarak toplam 44 hasta çalışmaya dahil edildi.

Olguların tümü genel, spinal ya da epidural anestezi altında ameliyat edildi. Hastalar supin pozisyonunda masaya yatırılarak dizleri 110130 derece kadar fleksiyona getirildi. Uygun saha temizliği ve örtülmeden sonra turnike uygulanmadan tüm vakalarda patella alt ucundan tuberositas tibiaya doğru yaklaşık $5 \mathrm{~cm}$ uzunluğunda tam orta hat boyunca cilt insizyonu yapıldı. Patellar tendon split ayrılarak tibia proksimalden ilk giriş kılavuzu ile giriş deliği açıldı ve oyma kılavuzu öncelikle kapalı redüksiyon ile yerleştirilmeye çalışıldı, üç denemede başarısız olunan vakalarda açık redüksiyon sağlandı. Kılavuz üzerinden tüm hastalara oymalı kilitli intramedüller fiksasyon yapıldı.

Tüm hastalar post-op erken dönemde klinik fizyoterapisti tarafından fizyoterapi programına alındı ve hastanın toleransına uygun olarak mobilize edildi. Hastanın taburculuğu sırasında uygun ev programı verilerek haftalık kontroller ile egzersizleri düzenlendi ve cerrah ile işbirliği içinde uygun ağılık aktarımı planlandı.

Hasta ve kırık ile ilgili tanımlayıcı bilgileri hazırlanan bir form aracılığı ile kaydedildi. Hastalara uygulanan veri kayıt formunda yaş, cinsiyet, kırık nedeni, ek yaralanmaların yeri, kırığın tipi, kırığın sınıflandırılması, hastanın ağırlık taşıma zamanı ve günlük aktiviteye geri dönüşü açısından kaydedildi. İyileşme süresi, radyolojik ve klinik bulgular incelenerek değerlendirildi. Radyolojik olarak iyileşme, ön-arka ve yan radyografide kallus 
formasyonu ve/veya kırık hattının kaybolması olarak değerlendirildi. Klinik iyileşme ise hastanın ağrısız tam yük verebilmesi ve günlük aktivitelerine dönebilmesi olarak değerlendirildi.

Ayrıca hastalar Johner-Wrush ve KarlstumOlerud Kriterlerine göre değerlendirildi. JohnerWrush kriterlerine göre (kaynamama, osteomiyelit, ampütasyon, ağrı, nörovasküler bozukluk, deformite, eklem hareketleri, yürüyüş ve aktivite) mükemmel, iyi, orta ve kötü olarak değerlendirildi. Karlstum-Olerud kriterlerine göre hastaların fonksiyonel sonuçları (36 puan mükemmel, 35-33 puan iyi, 32-30 puan tatmin edici, 29-27 puan orta ve 26-24 puan kötü) kaydedildi.

\section{Bulgular}

Hastaların yaş ortalaması $38.7 \pm 14.9$ yıl (1773) idi. 44 hastanın 10 (\%22.7) tanesi kadın ve $34(\% 77.3)$ tanesi erkek idi. Çalışmaya hastaların \%52.3'ünde (23) kırık sol tarafta iken \%47.7'sinde (21) kırık sağ tarafta idi. Tibia cisim kırığına yol açan en sık neden \%52.3 olarak trafik kazası (\%34.1 araç dışı, \%18.2 araç içi) bulundu (Tablo 1). Hastaların 16'sında (\%36.4) tibia $1 / 3$ orta cisim kırığı, 25 'inde $(\% 56.8)$ tibia $1 / 3$ distal kırık, 3 'ünde ise $(\% 6.8)$ ise tibia $1 / 3$ proksimal kırığı görüldü (Tablo 2).

Çalışmamızdaki hastaların ortalama kaynama süresi $342.27 \pm 115.46 \quad(180-600)$ gün olarak görüldü. Kaynama süresi ile yaş karşılaştırıldığında yaş ile kaynama süresi arasında pozitif yönde orta derecede anlamlı ilişki saptanmıştır $(r=0.389, p<0.05)$.

Hastaların postoperatif yük verme süresi ortalama $23.86 \pm 6.80$ (14-35) gün idi. Kaynama süresi ile yüklenme zamanı arasındaki ilişki istatistiksel olarak anlamlı bulunmuştur $(r=0.595$, $p<0.05)$. Erken yük vermeye başlayan hastalarda kırık kaynama zamanının azaldığı bulunmuştur. Tibia kırıklarının yerleşim yerine göre kaynama

Tablo 1. Hastaların ve hastalığın tanımlayıcı bilgileri

\begin{tabular}{lll}
\hline Değişkenler & Min-max & $\overline{\mathrm{x}} \pm \mathrm{SS}$ \\
\hline Yaş (yıl) & $180-600$ & $342,27 \pm 115,46$ \\
Kaynama süresi (gün) & $23,10-43,83$ & $30,32 \pm 6,91$ \\
Tam ağırlık aktarma süresi (gün) & $14-35$ & $23,86 \pm 6,80$ \\
& $\mathrm{~N}$ & $\%$ \\
Cinsiyet & & \\
Kadın & 10 & 22,7 \\
Erkek & 34 & 77,3 \\
Etkilenen taraf & & \\
Sağ & 23 & 52,3 \\
Sol & 21 & 47,7 \\
Kııık nedeni & & \\
Yüksekten düşme & 17 & 38,6 \\
Araç dışı trafik kazası & 15 & 34,1 \\
Araç içi trafik kazası & 8 & 18,2 \\
İş kazası & 2 & 4,5 \\
Ateşli silah yaralanması & 1 & 2,3 \\
Patolojik neden & 1 & 2,3 \\
Kırık yeri & & \\
Proksimal & 3 & 6,8 \\
Orta & 16 & 36,4 \\
Distal & 25 & 56,8 \\
Kırık tipi (AO) & & \\
A1 & 19 & 43,2 \\
A2 & 13 & 29,5 \\
A3 & 2 & 4,5 \\
B1 & 6 & 13,6 \\
B3 & 1 & 2,3 \\
C1 & 1 & 4,5 \\
C3 & 2 & \\
\hline
\end{tabular}


Tablo 2. Hastaların Johner-Wrush kriterlerine göre değerlendirilme sonuçları

\begin{tabular}{|c|c|c|c|c|}
\hline Johner-Wrush Kriterleri & $\begin{array}{l}\text { Mükemmel } \\
\mathrm{n}(\%)\end{array}$ & $\begin{array}{l}\text { İyi } \\
\text { n (\%) }\end{array}$ & $\begin{array}{l}\text { Orta } \\
\mathrm{n}(\%)\end{array}$ & $\begin{array}{l}\text { Kötü } \\
\text { n (\%) }\end{array}$ \\
\hline Kaynamama,osteomiyelit amputasyon & $43(97,7)$ & $1(2,3)$ & - & - \\
\hline \multicolumn{5}{|l|}{ Nörovasküler bozukluk } \\
\hline Deformite & $43(97,7)$ & $1(2,3)$ & - & - \\
\hline Varus/Valgus & $42(95,5)$ & $2(4,5)$ & - & - \\
\hline Anteversivon/Rekürvasvon & $44(100)$ & - & - & - \\
\hline Anteverslyon/Rekurvasyon & $40(90,9)$ & $4(9,1)$ & - & - \\
\hline Rotasyon/ Kısalık & $42(95,5)$ & $2(4,5)$ & - & - \\
\hline \multicolumn{5}{|l|}{ Hareket } \\
\hline \multicolumn{5}{|l|}{ Diz } \\
\hline Ayak bileği & $32(72,7)$ & $10(22,7)$ & $2(4,5)$ & - \\
\hline \multirow{2}{*}{ Subtalar eklem } & $26(59,1)$ & $16(36,4)$ & $2(4,5)$ & - \\
\hline & $31(70,5)$ & $13(29,5)$ & - & - \\
\hline \multicolumn{5}{|l|}{ Ağrı } \\
\hline Yürüme & $21(47,7)$ & $18(40,9)$ & $5(11,4)$ & - \\
\hline \multirow[t]{2}{*}{ Zorlayıcı aktivite } & $32(72,7)$ & $12(27,3)$ & - & - \\
\hline & & & & - \\
\hline
\end{tabular}

sürelerine bakıldığında kaynama sürelerinin proksimal 1/3 bölgesinde olan 3 kırıkta ortlama $13 \pm 2.6$ hafta, orta $1 / 3$ bölgesinde olan 16 kırıkta ortalama $13.1 \pm 4.6$ hafta, distal $1 / 3$ bölgesinde olan 25 kırıkta ortalama $10 \pm 2.8$ hafta olarak bulundu. Distal $1 / 3$ ve orta $1 / 3$ bölgesi kırıklar kaynama süreleri karşılaştırıldığında distal 1/3 bölgesindeki kırıkların istatistiksel olarak daha kısa sürede kaynadığı $(p<0,035)$ bulunmuştur.

Johner-Wrush kriterlerine göre 2 hastada $(0,5$ ve $1 \mathrm{~cm}$ ) kısalık saptandı. Hastaların hiç birinde klinik olarak rotasyon kusuruna rastlanmadı. Açılanmayı ölçerken radyografilerde proksimal ve distal parçalar arasındaki ön-arka ve yan planlardaki açılanmalar göz önünde bulunduruldu. Hastaların 2 tanesinde aks kusuruna rastlandı. Bu hastalardan birinde $3^{\circ}$ diğerinde ise $5^{\circ}$ valgus deformitesi mevcuttu. Diz hareketleri incelendiğinde 1 hastada ekstansiyon kaybı mevcuttu. İki hastada ise $15^{\circ}$ ve $20^{\circ}$ fleksiyon kısıtlılığı mevcuttu. Bir hastada ise ayak bileği hareketlerini ilgilendiren $5^{\circ}$ eklem hareket kısıtlılığı mevcuttu.

Hastaların, Karlstrum-Olerud'un fiziksel fonksiyonel değerlendirme skalasına göre aldıkları puanlar ise şöyleydi; 21 hasta $(\% 47,7) 36$ tam puan aldı, 14 hasta $(\% 31,8)$ ise 35-33 puan aralığında bulunup iyi olarak değerlendirildi. 1 hasta $(\% 2,3) \quad 32-30$ puan aralığında tatmin edici, 8 hasta $(\% 18,2)$ 29-27 puan aralığında olup orta olarak değerlendirildi. Hiçbir hasta kötü olarak değerlendirilmedi.

\section{Tartışma}

Çalışmamızda intramedüller çivileme uygulanan 44 tibia cisim kırığında \%79,5 hastada mükemmel ve iyi sonuç elde edilmiştir.. Hiçbir hastada kötü sonuç elde edilmedi. Hastalar ameliyattan sonra ortalama altıncı haftada tam yük vermeye başlamışlardır. Takip sürecinde bütün kırıkların kaynadığı bulunmuştur. Kırık lokasyonuna ve kaynama zamanına baktığımızda, çalışmamızda distal 1/3 bölge kırıklarının kaynama süresinin anlamlı derecede daha düşük olduğu saptanmıştır. Distal 1/3 kırıkları bölge itibarı ile daha daha fazla spongioz kemiğe sahiptir ve yumuşak doku örtünmesi daha iyidir ve böylece daha hızı kaynama olması beklenmektedir [3].

Tibia cisim kırklarında kaynamama ya da gecikmiş kaynama halen daha bir sorun olarak karşımıza çıkmaktadır [7, 8]. Kaynamama da ilk önerilen yöntem çivi değişimidir [9]. Gecikmiş kaynamada ya da gecikmiş kaynama olacağı ön görülen hastalarda dinamizasyon kaynamayı hızlandırmak için kullanılan seçeneklerin başında gelir [10]. Bu çalışmada dördüncü haftada istenilen kallus dokusu görülmeyen hastaların 17 tanesine distal dinamizasyon 
uygulanmıştır ve anlamlı şekilde kaynama süresi kısalmıştır.

Çalışmamızda hastalarımızın tümünde diz fleksiyonu $130^{\circ}$ üstünde bulundu, bir hastada 4 derece diz ekstansiyon kaybı saptandı. Bir hastada $5^{\circ}$ ayak bileği dorsifleksiyon kaybı ve $5^{\circ}$ subtalar eklem hareket kaybı görüldü, diğer hastalarımızda ayak plantar fleksiyon hareketi ve subtalar eklem hareketi sağlam taraf ile aynı bulundu. Alho ve ark. [11] yaptıkları çalışmada, kilitli intramedüller çivi ile tedavi edilen deplase tibia cisim kırıklarından sonra olguların \%10'unda diz ve ayak bileği eklemlerinde hareket kısıtlılığı olduğunu bildirmişlerdir. Literatürde, kapalı tibia kırıklarının intramedüller çivi ile yapılan tedavisi sonrası görülen enfeksiyon oranının \%0 ile \%4 arasında değiştiği, bu ameliyatlarda uygulanacak açık redüksiyonun ise enfeksiyon riskini arttırdığı bildirilmiştir [12]. Çalışmamızda kırıkların \%6 sının açık kırık olması, kullanılan açık redüksiyon oranının \%25 olmasına rağmen sadece 3 hastamızda $(\% 6,8)$ yüzeyel cilt enfeksiyonu görülmüştür ve hiçbir hastada enfeksiyona bağlı kaynamada gecikme veya kaynamama görülmemiştir. 11 kırıkta başarısız kapalı redüksiyon sonrası açık redüksiyona intiyaç duyulmuştur. Açık redüksiyon ile yara problemi arasında anlamlı bir ilişki bulunmamıştır. Ancak kaynama oranları açısından karşılaştırıldığında; açık redüksiyon grubunda ortalama kaynama süresi 13,1+4,9 hafta ve kapalı redüksiyon grubunda ortalama

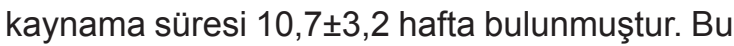
istatistiksel olarak görece anlamlı olsa da açık kırıkların hepsine açık redüksiyon uygulanmış olması istatistiksel sonucu etkilemektedir.

Oymalı kilitli intramedüller çivileme ile daha kalın çivi ve vida kullanıldığından, postoperatif dönemde çivi veya vida kırılması olasılığı daha azdır [13, 14]. Kilitli intramedüller çivilerin distal ve proksimal çivi delikleri kilitlenebildiğinden, kısalık, rotasyonel ve açısal deformite gelişim oranı en aza iner. Ameliyat esnasında açısal deformiteler mutlaka minimuma indirilmelidir. Aks kusuru olan vakalarda aynı zamanda eklem hareket kısıtııı̆ının anlamlı bir şekilde arttığı gösterilmiştir [15].

$\mathrm{Bu}$ çalışmanın sınırılıkları çalışmanın retrospektif olarak tasarlanmış olması ve tibia cisim kırıklarının konservatif olarak veya diğer cerrahi seçeneklerle tedavi eden bir kontrol grubunun bulunmamasıdır.
Uzun kemik kırıkları içerisinde tibia cisim kırıkları en sık görülenlerindendir [16]. İntramedüller çivi ile tedavi edilen 44 tibia cisim kırığı retrospektif olarak incelendi. Erken dönem harekete ve yük vermeye izin veren, düşük komplikasyon oranları ile birlikte, mevcut tedavide tibial cisim kırıklarında ilk seçenek olarak intramedüller çivi uygulamasını desteklemektedir.

Çıkar İlişkisi: Yazarlar çıkar ilişkisi olmadığını beyan ederler.

\section{Kaynaklar}

1. Court-Brown CM, Rimmer S, Prakash U, McQueen MM. The epidemiology of open long bone fractures. Injury 1998;29:529-534.

2. Larsen P, Elsoe R, Hansen SH, Graven-Nielsen T, Laessoe U, Rasmussen S. Incidence and epidemiology of tibial shaft fractures. Injury 2015;46:746-750.

3. Courtney PM, Bernstein J, Ahn J. In brief: closed tibial shaft fractures. Clin Orthop Relat Res 2011;469:35183521.

4. Green SA, Moore TA, Spohn PJ. Nonunion of the tibial shaft. Orthopedics 1988;11:1149-1157.

5. Hooper GJ, Keddell RG, Penny ID. Conservative management or closed nailing for tibial shaft fractures. A randomised prospective trial. J Bone Joint Surg $\mathrm{Br}$ 1991;73:83-85.

6. Bhandari M, Guyatt G, Tornetta P, et al. Randomized trial of reamed and unreamed intramedullary nailing of tibial shaft fractures. J Bone Joint Surg Am 2008;90:2567-2578.

7. Pobłocki K, Domaradzki M, Gawdzik J, Prochacki $\mathrm{P}$, Rajewski R. [Complications after intramedullary nailing of the tibia] Chir Narzadow Ruchu Ortop Pol 2011;76:274-277.

8. Vaughn J, Gotha H, Cohen E, et al. Nail dynamization for delayed union and nonunion in femur and tibia fractures. Orthopedics 2016;39:e1117-1123.

9. Walker RM, Zdero R, McKee MD, Waddell JP, Schemitsch EH. Ideal tibial intramedullary nail insertion point varies with tibial rotation. J Orthop Trauma 2011;25:726-730.

10. Hernández-Vaquero D, Suárez-Vázquez A, IglesiasFernández S, García-García J, Cervero-Suárez J. Dynamisation and early weight-bearing in tibial reamed intramedullary nailing: Its safety and effect on fracture union. Injury 2012;43:63-67.

11. Alho A, Ekeland A, Stromsoe K, Folleras G, Thoresen BO. Locked intramedullary nailing for displaced tibial shaft fractures. J Bone Joint Surg Br 1990;72:805-809.

12. Elniel AR, Giannoudis PV. Open fractures of the lower extremity: Current management and clinical outcomes. EFORT Open Rev 2018;3:316-325. 
13. Whittle AP, Wester W, Russell TA. Fatigue failure in small diameter tibial nails. Clin Orthop Relat Res 1995;315:119-128.

14. Karlström G, Olerud S. Fractures of the tibial shaft; a critical evaluation of treatment alternatives. Clin Orthop Relat Res 1974;105:82-115.

15. Busse JW, Morton E, Lacchetti C, Guyatt GH, Bhandari M. Current management of tibial shaft fractures. A survey of 450 Canadian orthopedic trauma surgeons. Acta Orthopaedica 2008;79:689-694.

16. Kundu IK, Datta NK, Chowdhury AZ, Das KP, Tarik MM, Faisal MA. Close intramedullary interlocking nailing versus locking compression plating in the treatment of closed fracture shaft of the tibia. Mymensingh Med J 2016;25:495-49 